too. Brian Marsden once said "To the man in the street the Solar System consists of Mars, the rings of Saturn and Halley's comet". Comets fascinate people and the next few years will see a flood of books, television programmes and newspaper articles on the subject.

Nigel Calder and the BBC are in the vanguard and The Comet is Coming! is the book of the television programme that is to be shown first on BBC2 in mid-1981. The book is excellent. Calder has a beautiful turn of phrase and often had me chuckling. The text is non-mathematical and infectiously readable. The illustrations have been carefully selected and many are new to me - not for Calder is the regurgitation of the old faithful. The style is journalistic but you are never left in doubt that the author is a sensible scientist.

IMAGE
UNAVAILABLE
FOR
COPYRIGHT
REASONS

Portent of a new King? Detail from the Bayeux tapestry showing the appearance of Halley's comet.

Halley's comet and its like are ostentatious and elusive and because of this they create a no-man's-land of speculation where crazy ideas may be fantasies or brilliant insights. This book is a sure guide to this no-man's-land and underlines the joys, mysteries and frustrations of cometary science. We read of the attitude of the superstitious who regard comets as telegrams from the Gods - disorders in heaven importing changes of times and states. The role of Edmund Halley is stressed, especially his work on orbits. The physical and chemical nature of comets and the suggestions as to their origin are reviewed, as are the problems of cometary discovery and observation. Fred Hoyle and Chandra Wickramasinghe's theory that comets could have brought life to Earth and are even today scattering disease over the globe through the influx of dust is discussed. Calder examines the consequences of a collision between the Earth and a comet; and special reference is obviously given to the demise of the dinosaurs about 65 million years ago!

The book is well referenced, well indexed and I recommend it strongly.

David W. Hughes is a Lecturer in Physics and Astronomy at the University of Sheffield.

\section{Star-spangled dream}

\section{Brian O'Leary}

Bound For the Stars. By Saul J. Adelman and Benjamin Adelman. Pp.335. ISBN hbk 0-13-080390-1; ISBN pbk 0-13080382-0. (Prentice-Hall: 1981.) Hbk $\$ 17.95$, £11.65; pbk \$8.95, £5.80.

"WE ARE too great a nation to limit ourselves to small dreams"' said President Reagan in his inaugural address. Amongst the budget slashing that has followed, it is difficult to imagine just what dreams $\mathrm{Mr}$ Reagan has in mind.

One thing is clear: there is no shortage of big dreams in space. Sound engineering concepts wait for their political and commercial opportunity. Once they are triggered, we can expect to witness an explosive renaissance in the high frontier. The question is not whether it will or should happen; it is when, how and by whom. Soviet-American political and military pressures mean we are in space to stay.

Different writers, however, have different goals. Gerard K. O'Neill, in The High Frontier, argues the case for satellite solar power stations and space habitats manufactured in space from lunar materials. Carl Sagan, in Cosmos, describes the excitement in expanding scientific programmes in modern astronomy, the search for extraterrestrial intelligence and unmanned planetary exploration. In The Fertile Stars, I show how asteroid mining and retrieval could provide the key to expanding the limits to growth of the world supply of energy, food and raw materials, to pave the way to space colonies and manned planetary exploration. Saul and Benjamin Adelman have a rather less accessible dream to offer; Bound for the Stars champions interstellar travel as the primary goal for future space activity.

There is little question that NASA's lack of a well-defined objective has hurt the American space program immensely. The lunar-landing commitment made by President Kennedy in 1961 (and completed eight short years later) was the last grand goal of space. We are now seeing the final vestiges of Apollo momentum petering out - the Voyager Saturn fly-bys will be the last American planetary probes to return new data for at least another five years.

Apart from the space shuttle, the US civilian space programme is virtually dead, while the Soviets, Europeans and Japanese move steadily forward. For example, all three plan a Halley's comet mission during its once-in-a-lifetime appearance in 1985 and 1986; budget cuts have grounded an American Halley probe. The Adelmans say these retrenchments can be ascribed to shortsighted year-to-year planning in the US federal government, and contrast this with the project-approval system of the European Space Agency. They stress the importance of changing NASA's charter to protect it from the lack of continuity it suffers from the annual budget cycle.

The best feature of the book is its wealth of detail on concepts of interplanetary and interstellar travel. The authors trace the history of the development of propulsion systems and navigational techniques with skill and perceptiveness. Most of the concepts have not flown. They describe, for example, the ill-fated Orion Project (in which exploding atomic bombs propel a large spaceship) as a "science orphan no one wanted to adopt".

The Adelmans' stand that interstellar travel should be the basic unifying aim for future space activity is controversial. Because starships are well beyond our current technological capability, many decision-makers will not accept such a heady goal. By contrast, Apollo was - and manned Mars landings, asteroid mining, space industrialization, space colonies and satellite solar power are - feasible projects which could use today's technology.

The first few chapters of the book are a smorgasbord of what appear to be afterthoughts. The authors skip rapidly from the origin of life to the search for extraterrestrial intelligence to a survey of the Solar System, back to life in space, plans for biological experiments aboard Spacelab, controlled ecologies, Solar System travel, space colonies and so forth.

These sections are weak, covering the subjects incoherently with misleading and biased remarks: for example, the belief that all life must be carbon-based and depend on water (see Life Beyond Earth by Gerald Feinberg and Robert Shapiro for a different view); "Dr Carl Sagan of Cornell University believes that about a million civilizations exist in the Galaxy on the same or more advanced level than Earth civilization" (p.17, too strong); "The galactic cosmic rays from outside the solar system are not a serious hazard, even for voyages lasting more than a year" (p.41, not true). In addition, they show a strong bias against satellite solar power and for nuclear power (pp.80-85) which, in the United States, might prove politically unacceptable.

The real strength of the book, then, is in its thorough discussion of the prospects of interstellar travel. I have been looking for a handy reference on the subject, and this is most certainly the best available. I applaud the Adelmans' remarks about the importance of keeping the space programme alive and that we need a goal to work toward.

I believe political and military pressures are the foot in the door, economic will become the driver (space industriaiization) and the thorough exploration of the Universe will be the ultimate and most fulfilling by-product.

In spite of all the budget-cutting and pessimism, we have some ideas. The Adelmans' treatment of interstellar travel in this new book is one of them.

Brian O'Leary is a former scientist-astronaut, and author of The Fertile Stars, to be published in June. 